\title{
Perceived Peer Exclusion as Predictor of Students' Help-Seeking Strategies in Higher Education
}

\author{
Differences by Gender and University Major
}

\author{
Lysann Zander@i and Elisabeth Höhne®
}

Division of Empirical Educational Research, Institute of Education, Leibniz Universität Hannover, Germany

\begin{abstract}
Feeling excluded by fellow students may be associated with lower levels of adaptive help-seeking. In a cross-sectional study, we compared self-reported help-seeking strategies (autonomy-oriented, dependency-oriented, help-seeking avoidance) among $N=418$ students in 25 seminar and tutorial groups in the undergraduate introductory courses of two subject domains: computer science and education. Analyses showed that, overall, students reported lower autonomy-oriented help-seeking and higher help-seeking avoidance in computer science than in education. In computer science, perceived peer exclusion predicted more help-seeking avoidance among both male and female students and less autonomy-oriented help-seeking among females. In education, however, perceived peer exclusion was a significant predictor of both male and female students' lower autonomy-oriented help-seeking. Results suggest that, in computer science, help-seeking appears to have an "image problem" signaling competence-related inferiority rather than being a form of effective selfregulated learning. Implications for enhancing adaptive help exchange cultures in computer science are discussed.
\end{abstract}

Keywords: social and academic exclusion, help-seeking, higher education, computer science, education

Wahrgenommene Peer-Exklusion als Prädiktor von Hilfesuchstrategien in der Hochschulbildung. Unterschiede nach Geschlecht und Fächerdomäne

Zusammenfassung: Die Exklusion durch Mitstudierende kann mit einem geringeren Ausmaß an adaptiver Hilfesuche einhergehen. In einer Querschnittsstudie mit $N=418$ Studierenden in 25 Seminargruppen haben wir selbstberichtete Hilfesuchstrategien (autonomieorientiert, dependenzorientiert, vermeidend) in zwei unterschiedlichen Fächerdomänen untersucht: Informatik und Pädagogik. Unsere Analysen zeigen, dass Informatikstudierende weniger autonomieorientierte Hilfesuche berichteten sowie mehr Vermeidung von Hilfesuche als Pädagogikstudierende. In Bezug auf die wahrgenommene Exklusion im Fach Informatik zeigte sich, dass diese sowohl für männliche als auch weibliche Studierende prädiktiv für die Hilfesuchvermeidung ist sowie für weibliche Studierende zudem eine geringere autonomieorientierte Hilfesuche vorhersagt. In der Pädagogik war die wahrgenommene Exklusion hingegen relevanter Prädiktor einer geringeren autonomieorientierten Hilfesuche für Studierende beider Geschlechter. Unsere Ergebnisse deuten darauf hin, dass die Suche nach fachlicher Hilfe in der Informatik insofern ein „Imageproblem“ zu haben scheint als dass sie als fachliche Unterlegenheit wahrgenommen wird anstatt als effektive Form selbstregulierten Lernens. Implikationen für die Steigerung adaptiven Hilfeaustausches in der Informatik werden diskutiert.

Schlüsselwörter: Soziale und fachliche Exklusion, Hilfesuche, Hochschulbildung, Informatik, Erziehungswissenschaften

The first year in higher education is a challenging transition period. Students must meet the requirements of the study program while also adapting to a new social life (Christie et al., 2004; Rausch \& Hamilton, 2006). Often for the first time, students cannot draw back on existing peer groups and cliques to help them master challenging course content. While this transition is challenging for many students (Strayhorn, 2018), much research has demonstrated that additional obstacles emerge for students who belong to a minority: frequently, these students doubt their belonging to the new learning environment, catalyzed by experiencing greater social exclusion and their perceived lower academic aptitude compared to their peers (Gopalan \& Brady, 2020; Höhne $\&$ Zander, 2019). Forming effective helping relations with fellow students can be important in managing these challenges (e.g., Brouwer et al., 2018; Lomi et al., 2011) because they create opportunities for social interaction, the exchange of resources among fellow students (e.g., Borgatti \& Lopez-Kidwell, 2011; Zander et al., 2018), and positively affect academic outcomes (Thomas, 2000). Yet, perceived exclusion during the first year of study may 
hinder students from forming effective helping relations with their peers. On the other hand, contextual variables, such as a collaborative and mastery-oriented learning environment (Ames, 1992; Ryan \& Shim, 2012), as well as a focus on growth potential instead of inherent ability (Covarrubias et al., 2019), have been shown to promote adaptive help-seeking.

In this article, we investigate the relationship between perceived peer exclusion and help-seeking strategies. Our study extends previous research by taking a closer look at the quality of help students seek from their peers, and by comparing the psychological situation of male and female students who constitute a minority in two strongly genderconnoted domains: computer science and education. We suggest that a comparison of these domains is particularly interesting because recent research on domain-specific ability beliefs found a high emphasis on "brilliance" as a requirement for success in STEM domains (science, technology, engineering, and mathematics; Deiglmayr et al., 2019), whereas this should be less the case in HEED domains (healthcare, elementary education, and the domestic spheres).

\section{Theoretical Background}

\section{Social Exclusion and Its Relation to Help-Seeking Among Peers}

In private as well as academic contexts, social relationships provide students with valuable resources to cope with challenges and stressful situations (Wesselmann et al., 2019). Yet, when transitioning into the university environment, first-year students, who often need to form new peer networks on campus, may worry about making friends, feeling disconnected (Strayhorn, 2018), and even feeling socially excluded. As a consequence, their fundamental need to belong (Baumeister \& Leary, 1995) may be violated. Social exclusion is a broad concept, comprising various negative social experiences signaling interpersonal or emotional devaluation (Riva \& Eck, 2016). It can involve forms of direct, rejection-based experiences or indirect, ostracism-based experiences, such as feeling ignored by others (Wesselmann et al., 2019). In university contexts, peer friendships have been shown to emerge out of collaborative academic exchanges (Zander et al., 2018). Furthermore, research has shown that students who feel rejected or excluded by their peers report lower academic self-competence, academic self-concepts, achievement motivation, and belonging (Höhne \& Zander, 2019; Walton \& Cohen, 2007; Wesselmann et al., 2019), ultimately resulting in lower achievement (Buhs, 2005;
Flook et al., 2005; Gopalan \& Brady, 2020; Walton \& Brady, 2020). Hence, we argue that sensing that one is not part of existing private off-campus or collaborative exchanges to tackle academic challenges can also hold students back from seeking adaptive help from their fellow students in academic settings.

A growing body of research documents that helpseeking should be considered an important and effective strategy of self-regulated learning, and that it should no longer be understood as evidencing academic inadequacy or dependency of the help-seeker. Yet, help-seeking differs from other regulation strategies in that it involves some form of social interaction and potentially stigmatizes the learner as incompetent (cf. Karabenick \& Gonida, 2018; Nadler, 2015). Help-seeking requires not only (meta-)cognitive competencies, e.g., to identify when and in which form help is needed as well as to evaluate the success or failure of the help-seeking attempt; it also requires the affective-emotional resources to cope with the potential threats to self-esteem and the fear of appearing incompetent when asking ostensibly betterperforming others for help (Karabenick \& Gonida, 2018). In a study with adolescents, Ryan and Pintrich (1997) showed that students who were unsure of themselves both cognitively and socially - were more likely to feel threatened when asking their peers for help. Moreover, a recent qualitative study examined theories that high school students used to describe and explain when they did and did not ask for help when struggling with course content in math classes (Peeters et al., 2020). Their analyses uncovered the strong tension between the expected benefits of help-seeking and potential psychological risks that students experienced in mathematics classes.

Drawing on the research discussed, we argue that, overall, students who feel excluded from the academic and private exchanges of their fellow students are less likely to take the additional psychological risk of asking for (adaptive) help from their peers.

\section{Help-Seeking in Gender-Stereotyped STEM and HEED Domains: Minority $\neq$ Minority?}

The role of contextual affordances in help-seeking is being increasingly recognized (Karabenick \& Gonida, 2018; Smalley \& Hopkins, 2020; Zusho \& Barnett, 2011). We expect that the psychological barrier for students to seek help from their peers is further heightened in learning environments that stress the importance of talent over effort for successful academic work. Here, seeking help could be more strongly interpreted as signaling a lack of inherent ability to cope with challenging assignments 
and classwork. Recent research suggests that such learning climates are more frequently found in STEM domains (Covarrubias et al., 2019; Deiglmayr et al., 2019). Thus, adaptive help-seeking should be less likely in STEM domains overall. However, we expect the situation to be intensified for minority students who face a negative ability-related stereotype.

Whereas female students constitute a clear minority in the computer sciences, male students do in the educational sciences. In Germany, only $18.64 \%$ of the students in computer science are women (Federal Statistical Office of Germany, 2019). In contrast, women are overrepresented in educational fields, particularly among the group of students studying educational sciences, primary-school pedagogy, or special needs education, where men constitute a numerical minority with an average share of $20.3 \%$ (Federal Statistical Office of Germany, 2019). It is thus not surprising that, overall, HEED domains are perceived as feminine (Chernyak-Hai et al., 2017; Tellhed et al., 2017), whereas STEM domains are perceived as masculine (Degner et al., 2019; Nosek et al., 2002; Nosek et al., 2009). Correspondingly, men in STEM are stereotypically expected to outperform women in these domains, resulting in an ability-related status difference between women and men (e.g., Bloodhart et al., 2020). Less clear, however, is whether male students in HEED domains are also confronted with negative ability-related stereotypes.

Several studies suggested that the detrimental psychological consequences of being in a numerical minority are hitting women in STEM domains harder than men in HEED domains. For example, one study (Tellhed et al., 2017) investigated ability-related beliefs and concerns about fitting in socially as mediators of male and female students' differential interest in STEM and HEED majors in a representative sample of 1,327 Swedish high school students. The authors found that interest in STEM was strongly related to female students' lower self-efficacy for STEM careers, but that self-efficacy was not a significant mediator of gender differences in interest in HEED. In a sample of 221 prospective teachers of special needs education, Zander \& Höhne (2021) found that, although in a minority, male students evaluated themselves to have a significantly higher performance potential than their fellow students compared to female students. The higher their perceived potential in comparison to their peers, the less they felt they belonged to their study program. These results stand in stark contrast to the typical findings for female students in STEM domains, where belonging uncertainty is also caused by a perceived academic mismatch - albeit in the form of worries about academic underachievement and inferiority (Banchefsky et al., 2019; Höhne \& Zander, 2019). Moreover, researchers suggested that students who belong to minority groups facing a negative ability-related stereotype can be particularly sensitive to the quality of their social bonds in challenging and achievement-oriented environments. According to the cues hypothesis, such settings can increase minority students' vulnerability to subtle situational cues that signal a lack of social connectedness (Murphy et al., 2007; Murphy \& Taylor, 2012). Therefore, students who feel excluded from the social and academic exchanges of their - possibly - "brilliant" fellow students should be even more likely to perceive help-seeking as risky (Peeters et al., 2020). Based on previous findings, we propose that this is the case for female students in STEM but not for male students in HEED domains. We therefore predicted that female students as a minority in the computer sciences but not male students as a minority in the domain of education should report less adaptive helpseeking when feeling excluded by their peers.

\section{A Closer Look at Help-Seeking Relations Through the Lens of Social Status}

When students decide to ask fellow students for help, not all forms of help-seeking are adaptive. Research has differentiated two types of help-seeking (e.g., Karabenick \& Newman, 2009; Nelson-Le Gall, 1981): the first, the "fast" or "executive" form, where students seeking to quickly complete a task and to avoid criticism simply ask peers (or teachers) for the correct solution; the second, the "slow" or "instrumental" form, where students seeking to master the task on their own and to understand the solution process ask their peers (or teachers) for just enough cues to be able to proceed with the task at hand autonomously. While these two forms of help-seeking have immediate consequences for students' learning progress and achievement (e.g., Ryan \& Shim, 2012; Webb \& Mastergeorge, 2003), they are also affected by students' social status. Nadler (2002) conceptualized the first form as dependency-oriented help because the helpseeker remains dependent on the help-giver, thus maintaining the status hierarchy. Nadler conceptualized the second form as autonomy-oriented help because it stimulates individual learning processes, strengthens the autonomy of help-seekers, increases their academic status, and allows them to help others in turn (see also Zander et al., 2017). Autonomy-oriented but not dependency-oriented help-seeking can thus be understood as an adaptive self-regulation strategy in terms of learning outcomes (Karabenick \& Newman, 2009; Kiefer \& Shim, 2016; Zimmerman \& Schunk, 1989), which is positively related to academic self-efficacy as well as students' integration 
into their academic peer networks (cf. Zander et al., 2018).

\section{Gendered Patterns of Help-Seeking Among Peers}

In the past, much research investigated male and female students' help-seeking tendencies in secondary and tertiary education. Even among university students, helpseeking can be affected by (traditional) gender roles (cf. Brown et al., 2020; Shnabel et al., 2016), according to which the male identity is traditionally associated with autonomy and self-reliance (Amemiya \& Wang, 2017). At the same time, studies in secondary education showed that "effortless achieving" is not only more in line with the male gender role, but also entails psychological benefits for boys (Heyder \& Kessels, 2016). From this viewpoint, help-seeking is perceived as incompatible with the autonomous male gender role (Kessels \& Steinmayr, 2013), and, accordingly, adaptive help-seeking strategies and behaviors are more frequently found among girls (Kiefer \& Shim, 2016; van Rijsewijk et al., 2016). More than in lower-level schools, depending on the field of study, university classrooms can show stark asymmetries regarding the share of male and female students. Scaling up the reported findings, it could be argued that the exchange of adaptive help more likely occurs in domains in which the majority of students are women, such as education. In contrast, higher levels of help-seeking avoidance and lower levels of adaptive help-seeking would be expected in domains with a larger share of male students, such as computer science.

\section{The Present Research}

The present study examined university students' different help-seeking strategies in the two gendered domains of computer science and education, to determine how perceived social and academic exclusion by fellow students affects seeking help among one's peers. Based on the research discussed, we expected that, overall, students would show lower levels of autonomy-oriented help-seeking (H1a) and higher levels of help-seeking avoidance (H1b) in the computer sciences than in the education field. We further predicted that higher levels of perceived peer exclusion would predict lower levels of autonomy-oriented help-seeking (H2a) and higher levels of help-seeking avoidance (H2b) in the field of education. Finally, we predicted that, among female students as a minority in the computer sciences but not among male students as a minority in the educational sciences, higher levels of peer exclusion would predict lower levels of autonomy-oriented help-seeking (H3a) and higher levels of help-seeking avoidance (H3b). We did not have a domain-specific prediction for dependency-oriented help, because we expected this type of help to be generally less frequent in higher education.

Within the framework of self-regulated learning, selfefficacy has proved to be related to help-seeking in both school (e.g., Karabenick \& Gonida, 2018) and university settings (e.g., Brouwer et al., 2016). Several studies found that students with higher self-efficacy are more likely to seek help (Linnenbrink \& Pintrich, 2003; Pintrich \& Zusho, 2007; Zander et al., 2019), whereas other studies could not find empirical support for the hypothesis that self-efficacy would increase help-seeking behavior (Cleavenger et al., 2007). Likewise, some previous research identified achievement as a positive predictor of helpseeking (Zander et al., 2019), one reason being the better (meta-)cognitive skills of higher-achieving students enabling them to better identify when help is needed and how it can be obtained. Other research showed an inverted relationship with lower-achieving students being more likely to seek help (Newman \& Schwager, 1995). Given the inconclusiveness of previous findings, we considered both domain-specific academic self-efficacy and academic achievement as covariates when examining university students' help-seeking strategies.

\section{Method}

\section{Participants}

A total of 447 undergraduate students in 25 seminars and tutorials participated in the study. 29 of them did not indicate their gender and were excluded from the analyses. The final sample consisted of 200 (149 male, 51 female) computer science students and 218 (35 male, 183 female) students enrolled in either educational science, primary-school pedagogy, or special needs education. Students were between 17 and 47 years old, with an average age of 21.72 years $(S D=4.77)$. The overall participation rate of students present was $85.03 \%$.

\section{Procedure}

The study was conducted in winter term 2017/18 at the Institute of Computer Science and the Department of Education at a large German university. In both subject domains, questionnaires were distributed in the second 


\section{Comparison: STEM vs. HEED domain}

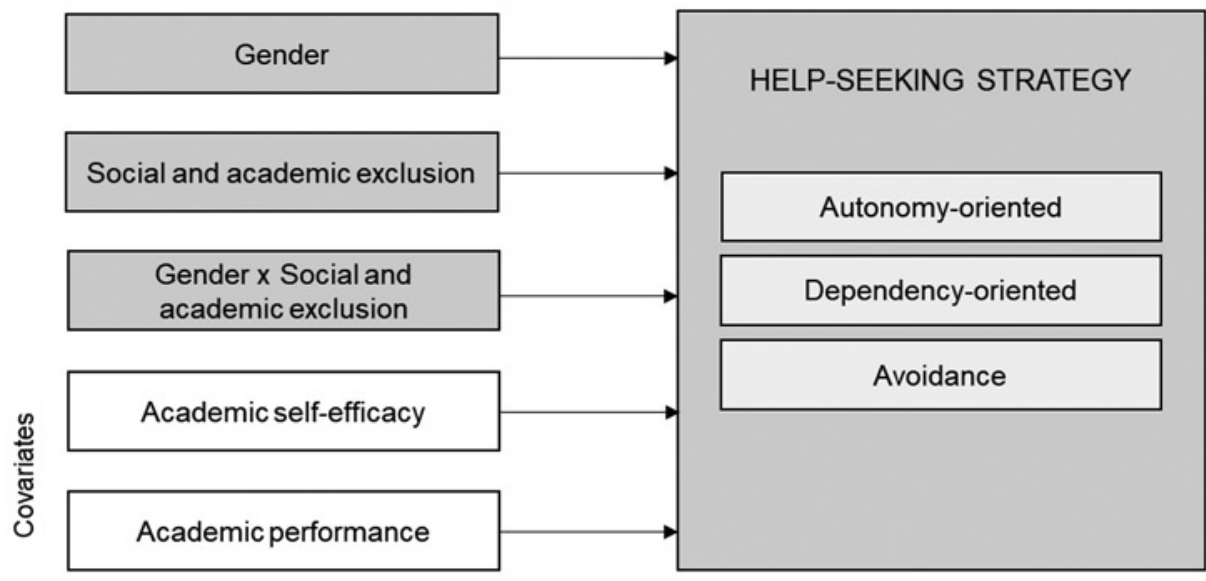

Figure 1. Schematic depiction of the research model.

and third week of the lecture period during or after a total of 25 mandatory seminars and tutorials of the first-year students. All students were asked to participate in a study on their "first impressions and experiences at university" and were told that its purpose was to improve the studying conditions. Before students gave their written consent to participate, they were assured of voluntary participation, the anonymity of their responses, confidentiality in data handling, and their right to withdraw from the study at any time without giving any reason.

The paper-and-pencil questionnaire took students between 15 and 20 minutes to complete. As an incentive, a book voucher was raffled among all participants.

\section{Measures}

\section{Help-Seeking Strategies}

The different help-seeking strategies were measured using an adapted version of the Help-Seeking Scale by Komissarouk et al. (2017). Whereas the original scale consists of 14 items (with an unequally distributed number of items among the three help-seeking strategies), we decided to measure each of the three strategies with the same number of items and chose the respective four items per help-seeking strategy that showed the highest factor loadings in the validation process (cf. Komissarouk et al., 2017). Because we were interested in help-seeking regarding academic tasks and problems among peers at university rather than general helpseeking in daily life, the content of the scale was adapted to the context of the university and help-seeking behavior from fellow students. The subscales measuring autonomy-oriented help-seeking (e.g., "When I encounter a subject-specific problem in this seminar/tutorial, I ask other students who have had a similar problem how they solved it and try to learn from their experience"), dependency-oriented help-seeking (e.g., "I prefer to get help and support from other students, rather than to take control and arrive at my own solutions"), and avoidance of seeking help from fellow students (e.g., "It is more important for me to accomplish things on my own, even if I would be better off receiving help from other students") showed a sufficient to good internal consistency ( $\alpha$ between .659 and .793), after one item with the lowest item-total correlation ( $r$ between .174 and .456) was removed from each subscale. On each of the three subscales, students indicated their agreement on a 5-point Likert response scale ( $1=$ strongly disagree, $5=$ strongly agree). The intraclass correlation (ICC) for students within seminar/tutorial groups was .027 for autonomy-oriented help-seeking, .002 for dependency-oriented help-seeking, and .122 for help-seeking avoidance.

\section{Social and Academic Exclusion}

Students' perceived exclusion from nonacademic social activities and subject-related exchange by fellow students was assessed using a scale developed for the context of higher education (Höhne \& Zander, 2019). The measure consists of four items (e.g., "Sometimes I have the feeling that other students meet privately, and I am not included", "I have already noticed that other students engage in 
subject-related exchange, and I am not included"), used a 5 -point Likert response scale $(1=$ strongly disagree, $5=$ strongly agree), and was found to be internally consistent $(\alpha=.895)$.

\section{Domain-Specific Academic Self-Efficacy}

We used an adapted measure by Jerusalem and Schwarzer (1986) to assess domain-specific academic self-efficacy, which refers to students' beliefs about their ability to perform academic tasks at designated levels. Whereas the original scale consists of seven items altogether, here we applied a shortened two-item version: "I am confident that I have the competencies to perform well in this subject" and "I can cope with difficult situations and challenges in my studies when I try hard". Both items used a 5-point Likert response scale $(1=$ strongly disagree, $5=$ strongly agree), and formed a sufficiently reliable scale $(\alpha=.720)$.

\section{Academic Performance}

Because our sample mainly consisted of first-year university students $(88.3 \%)$ who had not yet received any grades at their university, we used students' self-reported Abitur grade as a proxy variable for previous academic performance. In accordance with the grading in Germany's educational system, lower values indicate better performance.

The amount of missing data on the variables described above ranged from $0.5 \%$ (help-seeking avoidance) to $7.9 \%$ (academic performance) in our sample.

\section{Statistical Analyses}

Statistical analyses, unless stated differently, were performed using Mplus version 8.1 (Muthén \& Muthén, 1998-2017), using a robust maximum likelihood (MLR) estimator. First, we calculated descriptive statistics and bivariate correlations for all variables of interest. In addition, we tested mean differences and standardized mean differences ${ }^{1}$ between male and female students $(0=$ male, $1=$ female) as well as between the two subject domains $(0=$ computer science, 1 = education $)$ using simple linear regression analyses. Subsequently, we conducted a multilevel multiple-group multivariate linear regression analysis, stratified by subject domain, in which we regressed the three help-seeking strategies on gender, perceived social and academic exclusion as well as the interaction between gender and perceived exclusion, while controlling for students' domain-specific academic self-efficacy and academic performance. The regression models for the subject domains of computer science and education were estimated simultaneously using the GROUPING command within Mplus. A multiple-group analysis was used as a means of determining whether our models significantly differed between the two subject domains. This involved comparing the $\chi^{2}$ values between a model in which all coefficients were freely estimated and a model in which the coefficients were constrained to be equal across subject domains. The residual variances of the three dependent variables were allowed to correlate, which fully saturated our model. The hierarchical data structure of students (level-1 unit) nested within seminar or tutorial groups (level-2 unit), which may violate the assumption of independent observations (e.g., Snijders \& Bosker, 2012), was accounted for by using the TYPE $=$ COMPLEX command in Mplus. Because our analysis focused on effects within persons, and because we expected the relevant reference group for students at the beginning of their studies to be other students in their seminar or tutorial group rather than all students in their entire year or study program, all level-1 variables except the categorical variable of gender were group-mean centered. Accordingly, slopes are interpreted as the increase in the dependent variable associated with a oneunit increase in the independent variable - relative to the mean of the seminar or tutorial group (for the interpretation of the different centering approaches, see Park, 2008). Missing values were estimated using full information maximum likelihood estimation (FIML), which has been shown to be superior to other missing-data techniques, such as listwise or pairwise deletion and single imputation methods (Peugh \& Enders, 2004; Schafer \& Graham, 2002). To avoid listwise deletion of individuals with missing data on $\mathrm{x}$-variables, we treated independent variables as dependent variables within Mplus as a result of specifying the means and variances of the independent variables (Hox et al., 2015). Simple slopes tests for the significant interactions were conducted to test whether the slopes for male and female students were significantly different from 0 (cf. Aiken \& West, 1991). In addition, we visualized simple slopes using the web-based data visualization tool interActive (McCabe et al., 2018).

Standardized mean differences were calculated using Cohen's $d$ statistic, with small, medium, and large effect sizes (ES) being equivalent to $d$ $=0.20,0.50$, and 0.80, respectively (Cohen, 1988). ES were calculated using the following formula: $\Delta=\frac{\beta_{1}}{\sigma_{e}}$ (Tymms et al., 1997). 
Table 1. Means, standard deviations, and mean differences by gender per subject domain

\begin{tabular}{|c|c|c|c|c|c|c|c|}
\hline & & \multicolumn{3}{|c|}{ Help-seeking strategies } & \multirow[t]{2}{*}{ Social exclusion } & \multirow[t]{2}{*}{ Academic self-efficacy } & \multirow[t]{2}{*}{ Academic performance } \\
\hline & & Autonomy & Dependency & Avoidance & & & \\
\hline & $N$ & $M(S D)$ & $M(S D)$ & $M(S D)$ & $M(S D)$ & $M(S D)$ & $M(S D)$ \\
\hline \multicolumn{8}{|c|}{$\underline{\text { Computer Science }}$} \\
\hline Total & 200 & $3.65(.87)$ & $2.02(.78)$ & $2.49(.85)$ & $2.75(1.10)$ & $3.88(.76)$ & $2.20(.65)$ \\
\hline Males & 149 & $3.61(.88)$ & $1.99(.76)$ & $2.52(.88)$ & $2.78(1.12)$ & $3.95(.72)$ & $2.25(.66)$ \\
\hline Females & 51 & $3.77(.85)$ & $2.09(.83)$ & $2.40(.73)$ & $2.68(1.04)$ & $3.66(.83)$ & $2.07(.61)$ \\
\hline$B(S E)$ & & $.163(.09)$ & $.096(.13)$ & $-.114(.12)$ & $-.081(.14)$ & $-.301(.18)$ & $-.186(.14)$ \\
\hline$p$ & & .083 & .463 & .346 & .570 & .094 & .172 \\
\hline \multicolumn{8}{|c|}{ Education } \\
\hline Total & 218 & $3.89(.66)$ & $1.91(.66)$ & $1.89(.67)$ & $2.55(.98)$ & $4.18(.47)$ & $2.36(2.02)$ \\
\hline Males & 35 & $3.62(.81)$ & $1.87(.63)$ & $1.90(.71)$ & $2.42(1.01)$ & $4.28(.39)$ & $2.79(3.52)$ \\
\hline Females & 183 & $3.95(.61)$ & $1.92(.66)$ & $1.89(.66)$ & $2.57(.98)$ & $4.17(.48)$ & $2.27(1.52)$ \\
\hline$B(S E)$ & & $.327(.11)$ & $.050(.10)$ & $-.008(.11)$ & $.153(.13)$ & $-.114(.07)$ & $-.515(.66)$ \\
\hline$p$ & & $.002^{\star \star}$ & .633 & .937 & .249 & .092 & .432 \\
\hline Total & 418 & $3.78(.78)$ & $1.96(.72)$ & $2.18(.81)$ & $2.65(1.05)$ & $4.04(.64)$ & $2.29(1.54)$ \\
\hline Males & 184 & $3.61(.86)$ & $1.97(.74)$ & $2.40(.88)$ & $2.71(1.11)$ & $4.01(.68)$ & $2.37(1.73)$ \\
\hline Females & 234 & $3.91(.67)$ & $1.95(.70)$ & $2.00(.70)$ & $2.60(.99)$ & $4.06(.61)$ & $2.23(1.38)$ \\
\hline$B(S E)$ & & $.300(.06)$ & $-.013(.06)$ & $-.399(.08)$ & $-.107(.10)$ & $.041(.09)$ & $-.139(.17)$ \\
\hline$p$ & & $.000 * * *$ & .837 & $.000 * * *$ & .275 & .649 & .424 \\
\hline
\end{tabular}

Note. All values were estimated using Mplus and full information maximum likelihood estimation (FIML). Standard errors were adjusted for the hierarchical data structure. Gender: $0=$ male, $1=$ female. ${ }^{*} p \leq .01,{ }^{*} * x \leq .001$.

\section{Results}

\section{Descriptive Analyses}

Table 1 and Table 2 show the mean values, standard deviations, and mean differences. As can be seen, there were no significant mean differences between male and female students in the domain of computer science, whereas in our second domain, education, male students reported significantly less autonomy-oriented help-seeking within their seminar group than did female students $(B$ $=.327, p \leq .01, d=.506)$. When comparing the two subject domains, we found significant mean differences for autonomy-oriented help-seeking $(B=.244, p \leq .001, d=$ $.318)$ and help-seeking avoidance $(B=-.596, p \leq .001, d=$ $.787)$ in the expected direction: students in the domain of education reported more autonomy-oriented help-seeking (H1a) and less help-seeking avoidance (H1b) than students in the computer sciences, confirming our first two hypotheses. We found no difference between female students' autonomy-oriented help-seeking in the two subject domains $(B=.173, p=.094, d=.259)$, although female students in computer science did report higher help-seeking avoidance than females in education $(B=$ $-.510, p \leq .001, d=.757)$. This was also the case for male students in computer science compared to males in education $(B=-.619, p \leq .001, d=.728)$. Moreover, male students in the computer sciences reported more social and academic exclusion by their peers than those studying education $(B=-.353, p \leq .001, d=.321)$.

Table 3 presents the bivariate correlations between all variables of interest. Perceived social and academic exclusion significantly correlated with all three helpseeking strategies: negatively with autonomy-oriented help-seeking and positively with both dependency-oriented help-seeking and avoidance. Moreover, domain-specific academic self-efficacy proved to be positively correlated with autonomy-oriented help-seeking as well as negatively correlated with dependency-oriented helpseeking and perceived social and academic exclusion by fellow students. Because of the moderate correlations between some of the explanatory variables, we examined variance inflation factors (VIFs) for each of the regression models' predictors to quantify multicollinearity using SPSS (version 25.0; IBM Corp., 2017). With the lowest VIF-core being 1.013 and the highest being 1.634 , no significant inflation of standard errors due to nonorthogonality among the predictors was indicated. 
Table 2. Means, standard deviations, and mean differences by subject domain per gender

\begin{tabular}{|c|c|c|c|c|c|c|c|}
\hline & & \multicolumn{3}{|c|}{ Help-seeking strategies } & \multirow[t]{2}{*}{ Social exclusion } & \multirow[t]{2}{*}{ Academic self-efficacy } & \multirow[t]{2}{*}{ Academic performance } \\
\hline & & Autonomy & Dependency & Avoidance & & & \\
\hline & $N$ & $M(S D)$ & $M(S D)$ & $M(S D)$ & $M(S D)$ & $M(S D)$ & $M(S D)$ \\
\hline \multicolumn{8}{|l|}{ Males } \\
\hline Total & 184 & $3.61(.86)$ & $1.97(.74)$ & $2.40(.88)$ & $2.71(1.11)$ & $4.01(.68)$ & $2.37(1.73)$ \\
\hline Computer Sc. & 149 & $3.61(.88)$ & $1.99(.76)$ & $2.52(.88)$ & $2.78(1.12)$ & $3.95(.72)$ & $2.25(.66)$ \\
\hline Education & 35 & $3.62(.81)$ & $1.87(.63)$ & $1.90(.71)$ & $2.42(1.01)$ & $4.28(.39)$ & $2.79(3.52)$ \\
\hline$B(S E)$ & & $.011(.12)$ & $-.122(.09)$ & $-.619(.13)$ & $-.353(.11)$ & $.319(.08)$ & $.529(.61)$ \\
\hline$p$ & & .925 & .192 & $.000 * * *$ & $.001 * * *$ & $.000 * * *$ & .388 \\
\hline \multicolumn{8}{|l|}{ Females } \\
\hline Total & 234 & $3.91(.67)$ & $1.95(.70)$ & $2.00(.70)$ & $2.60(.99)$ & $4.06(.61)$ & $2.23(1.38)$ \\
\hline Computer Sc. & 51 & $3.77(.85)$ & $2.09(.83)$ & $2.40(.73)$ & $2.68(1.04)$ & $3.66(.83)$ & $2.07(.61)$ \\
\hline Education & 183 & $3.95(.61)$ & $1.92(.66)$ & $1.89(.66)$ & $2.57(.98)$ & $4.17(.48)$ & $2.27(1.52)$ \\
\hline$B(S E)$ & & $.173(.10)$ & $-.174(.13)$ & $-.510(.08)$ & $-.109(.17)$ & $.507(.15)$ & $.212(.16)$ \\
\hline$p$ & & .094 & .177 & $.000 * \star \star$ & .528 & $.001 * \star \star$ & .172 \\
\hline Total & 418 & $3.78(.78)$ & $1.96(.72)$ & $2.18(.81)$ & $2.65(1.05)$ & $4.04(.64)$ & $2.29(1.54)$ \\
\hline Computer Sc. & 200 & $3.65(.87)$ & $2.02(.78)$ & $2.49(.85)$ & $2.75(1.10)$ & $3.88(.76)$ & $2.20(.65)$ \\
\hline Education & 218 & $3.89(.66)$ & $1.91(.66)$ & $1.89(.67)$ & $2.55(.98)$ & $4.18(.47)$ & $2.36(2.02)$ \\
\hline$B(S E)$ & & $.244(.08)$ & $-.107(.06)$ & $-.596(.07)$ & $-.204(.11)$ & $.301(.06)$ & $.156(.13)$ \\
\hline$p$ & & $.001 * \star \star$ & .086 & $.000 * \star \star$ & .057 & $.000 \star \star \star$ & .226 \\
\hline
\end{tabular}

Note. All values were estimated using Mplus and full information maximum likelihood estimation (FIML). Standard errors were adjusted for the hierarchical data structure. Subject domain: $0=$ computer science, $1=$ education. ${ }^{* \star} p \leq .01,{ }^{*} * p \leq .001$.

Table 3. Correlations of the dependent and independent variables

\begin{tabular}{|c|c|c|c|c|c|c|c|c|c|}
\hline & 1 & 2 & 3 & 4 & 5 & 6 & 7 & 8 & VIF \\
\hline 1 Autonomy & 1 & .100 & $-.433 * \star \star *$ & 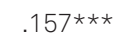 & $.191 * \star \star$ & $-.253 * \star \star$ & $.168^{\star * \star}$ & .032 & - \\
\hline 2 Dependency & & 1 & -.059 & -.074 & -.009 & $.106^{* *}$ & $-.357 * * *$ & .031 & - \\
\hline 3 Avoidance & & & 1 & $-.366 * \star \star$ & $-.243 * \star \star$ & 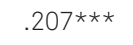 & -.047 & -.030 & - \\
\hline 4 Subject domain & & & & 1 & $.588^{\star \star \star}$ & -.097 & $.236 * \star \star$ & .048 & 1.634 \\
\hline 5 Gender & & & & & 1 & -.051 & .029 & -.042 & 1.525 \\
\hline 6 Social exclusion & & & & & & 1 & $-.161 \star \star$ & .014 & 1.026 \\
\hline 7 Acad. self-efficacy & & & & & & & 1 & .001 & 1.099 \\
\hline 8 Acad. performance & & & & & & & & 1 & 1.013 \\
\hline
\end{tabular}

Note. $N=418$. All values were estimated using Mplus and full information maximum likelihood estimation (FIML). Standard errors were adjusted for the hierarchical data structure. VIF = Variance inflation factor of the independent variables (variables 4-8; results were estimated using SPSS). Gender: $0=$ male, $1=$ female. Subject domain: $0=$ computer science, $1=$ education. ${ }^{* \star} p \leq .01,{ }^{*} * p \leq .001$.

\section{Multilevel Multiple-Group Multivariate Regression}

In the next step, we conducted a multilevel multiplegroup multivariate regression analysis, stratified by subject domain, in which the three help-seeking strategies were regressed on gender, perceived social and academic exclusion, the interaction between gender and perceived social and academic exclusion as well as our covariates domain-specific academic self-efficacy and academic performance (see Table 4). In line with our expectations
(H2a), our results show that, in the domain of education, perceived social and academic exclusion was a relevant predictor of both male and female students' autonomyoriented help-seeking ( $\beta=-.394, p \leq .01)$. In contrast to our predictions $(\mathrm{H} 2 \mathrm{~b})$, however, we did not find the perceived exclusion by fellow students to be predictive of educational science students' help-seeking avoidance ( $\beta=$ $.222, p=.220)$. In the domain of computer science, we found the interaction between gender and students' perceived exclusion to be predictive of autonomy-oriented help-seeking ( $\beta=-.260, p \leq .01)$, confirming our next 
Table 4. Multiple-group multivariate regression analysis predicting the three help-seeking strategies

\begin{tabular}{|c|c|c|c|c|c|c|c|c|c|}
\hline & \multicolumn{9}{|c|}{ Help-seeking strategies } \\
\hline & \multicolumn{3}{|c|}{ Autonomy } & \multicolumn{3}{|c|}{ Dependency } & \multicolumn{3}{|c|}{ Avoidance } \\
\hline & $B$ & $(S E)$ & $\beta$ & $B$ & $(S E)$ & $\beta$ & $B$ & $(S E)$ & $\beta$ \\
\hline \multicolumn{10}{|l|}{ Computer science } \\
\hline Gender & .214 & .082 & $.107 * \star$ & .018 & .137 & .010 & -.075 & .110 & -.038 \\
\hline Social exclusion & -.102 & .107 & -.126 & .030 & .047 & .042 & .171 & .057 & $.218 * *$ \\
\hline Gender x Social exclusion & -.461 & .151 & $-.260 * \star$ & .047 & .134 & .030 & .059 & .122 & .035 \\
\hline Academic self-efficacy & .182 & .079 & $.153^{\star}$ & -.409 & .063 & $-.389 * * *$ & .163 & .080 & $.142^{\star}$ \\
\hline Academic performance & .174 & .106 & .127 & .227 & .084 & $.186^{* *}$ & -.144 & .091 & -.109 \\
\hline \multicolumn{10}{|l|}{ Education } \\
\hline Gender & .399 & .113 & $.223 * \star \star$ & .018 & .105 & .010 & -.053 & .116 & -.029 \\
\hline Social exclusion & -.273 & .090 & $-.394 * \star$ & -.065 & .089 & -.094 & .156 & .123 & .222 \\
\hline Gender $\times$ Social exclusion & .191 & .108 & .247 & .100 & .112 & .130 & -.031 & .158 & -.040 \\
\hline Academic self-efficacy & .174 & .098 & .118 & -.259 & .093 & $-.176 * \star$ & -.132 & .135 & -.089 \\
\hline Academic performance & .002 & .011 & .007 & -.004 & .023 & -.011 & .006 & .018 & .018 \\
\hline$\overline{\chi^{2}(d f)}$ & \multicolumn{3}{|c|}{$173.16(31)^{\star \star \star \star}$} & \multicolumn{3}{|c|}{$161.01(31)^{\star \star \star}$} & \multicolumn{3}{|c|}{$190.62(31)^{\star \star \star}$} \\
\hline
\end{tabular}

Note. All values were estimated using Mplus and full information maximum likelihood estimation (FIML). Standard errors were adjusted for the hierarchical data structure. The last row indicates $\chi^{2}$ differences between a fully unconstrained model and a model assuming equal regression parameters between computer science and education. Gender: $0=$ male, $1=$ female. $R_{\text {Autonomy, computer Science }}^{2}=16.5 \%, R_{\text {Autonomy, Education }}^{2}=8.5 \%, R_{\text {Dependency, computer Science }}^{2}=21.6 \%$, $R_{\text {Dependency, Education }}^{2}=3.6 \%, R_{\text {Avoidance, Computer Science }}^{2}=7.8 \%, R_{\text {Avoidance, Education }}^{2}=4.2 \% .{ }^{\star} p \leq .05,{ }^{*} p \leq .01,{ }^{* \star *} p \leq .001$.

hypothesis (H3a). Thus, female computer science students with higher values of perceived exclusion from nonacademic social activities and subject-related exchange relative to their group mean were less likely to engage in autonomy-oriented help-seeking with their peers (see Figure 2); post-hoc simple slopes analyses confirmed this finding. In education, however, we found this pattern only by trend for male students ( $\beta=.247, p=$ .078). Against our expectations (H3b), in computer science, the relationship between perceived social and academic exclusion and help-seeking avoidance did not differ as a function of gender $(\beta=.035, p=.629)$. Rather, a significant main effect $(\beta=.218, p \leq .01)$ indicated that the perceived exclusion from social and academic activities with peers is a relevant predictor of both male and female computer science students' help-seeking avoidance. Our model explained a total of $8.5 \%$ (education) and $16.5 \%$ (computer science) of the variance in autonomy-oriented help-seeking, while it explained $4.2 \%$ (education) and $7.8 \%$ (computer science) of the variance in help-seeking avoidance.

In a final step, we examined whether the regression coefficients differed significantly between our two subject domains. For all three help-seeking strategies, $\chi^{2}$ statistics were significant $\left(\chi_{\text {autonomy }}^{2}(31)=173.16, p \leq .001 ; \chi_{\text {dependency }}^{2}\right.$ $\left.(31)=161.01, p \leq .001 ; \chi_{\text {avoidance }}^{2}(31)=190.62, p \leq .001\right)$, indicating significant cross-group differences.

\section{Discussion}

Help-seeking is an important strategy of self-regulated learning and positively related to various academic outcomes, including achievement (Ryan \& Shim, 2012; Webb \& Mastergeorge, 2003), though it carries the psychological risk of signaling competence-related inferiority. To date, little is known about both the degree to which feelings of social and academic exclusion can undermine students' willingness to take this risk and the role of the academic context. In the present study, we took a closer look at various help-seeking strategies among fellow students (autonomy-oriented, dependency-oriented, help-seeking avoidance), and compared the situation of male and female minority students in two counterstereotypical domains: the male-connoted STEM domain of computer science and the female-connoted HEED domain of education.

\section{Do Helping Relations Differ in Education and Computer Science Classrooms?}

In our analyses, we found stark differences between students' help-seeking strategies in the two different subject domains: students sought less autonomy-oriented help and reported more help-seeking avoidance in computer science than in education. Students' reluctance to seek help from their fellow students in computer science 


\section{Computer Science}

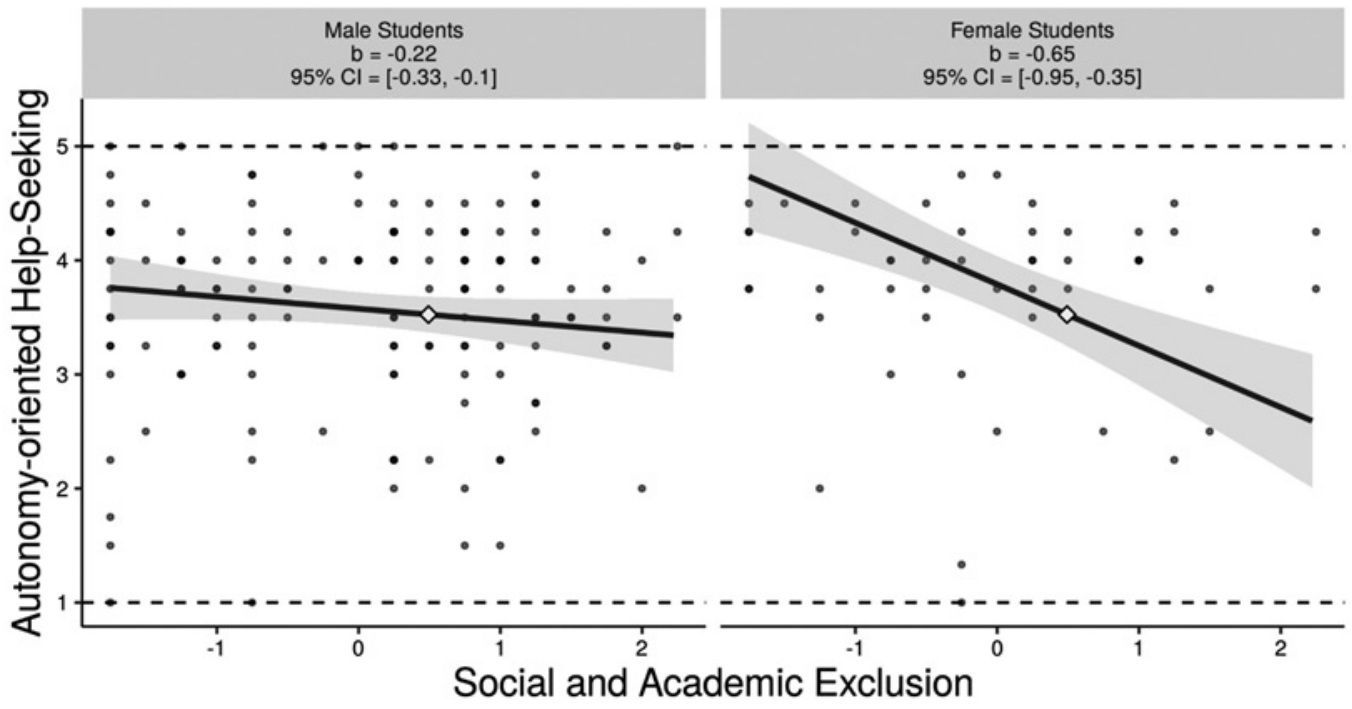

Education

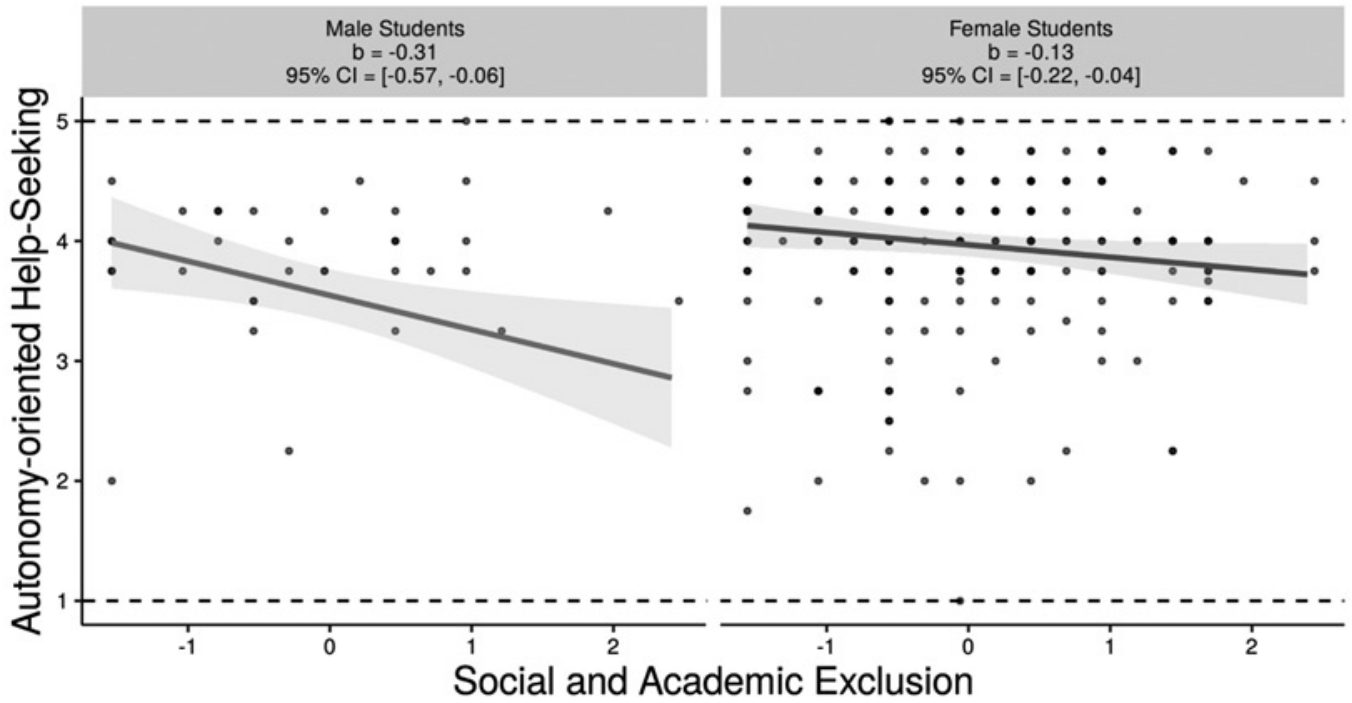

Figure 2. Simple slopes graphs depicting the relationship between social and academic exclusion and autonomy-oriented help-seeking, both in the domains of computer science and education. In each panel, simple slopes are displayed for male and female students. Academic self-efficacy and previous academic performance were entered as covariates.

$\mathrm{Cl}=$ confidence interval.

could be both an expression or a cause of the "chilly" climate reported for STEM domains (e.g., Walton et al., 2015). One potential explanation, found to prevail in STEM fields, is the belief that successful performance requires innate "brilliance" rather than effort (Deiglmayr et al., 2019). Such beliefs should be more compatible with self-reliance and less with asking "brilliant" others for help. In support of this notion, recent studies found that students with growth mindsets (cf. Dweck, 1999), that is, who believe that people can work hard on improving their talents, were more frequently nominated as preferred helpers in university classrooms (Zander et al., 2018), and that growth messages in STEM environments increased academic help-seeking (Covarrubias et al., 2019). Further, it has been argued that adaptive help-seeking is more likely to occur in environments in which the act of seeking help appears to be frequent and usual, allowing students to attribute the need for help to external causes, such as task difficulty rather than individual incompetence (cf. Cleavenger et al., 2007). In our study, this appears to be 
the case in education, where students reported more autonomy-oriented help-seeking and less help-seeking avoidance than in the computer sciences. Gendered patterns of help-seeking tendencies provide a second potential explanation for the identified differences: the larger share of male students found to avoid help-seeking from peers more frequently than female students (Kiefer \& Shim, 2016; van Rijsewijk et al., 2016). This could scale up to a generally higher level of help-seeking avoidance in computer science, which is then being accepted by female students.

\section{Does Exclusion Matter?}

Although the cross-sectional study design forbids inferences about causality, overall, our analyses do indicate that students seek less adaptive help from peers when they feel excluded from their fellow students' academic and social exchanges. The more students feel excluded from exchanges with their fellow students, the less they seem to have the affective-emotional resources to cope with the potential threats to self-esteem and the fear to appear incompetent when asking ostensibly better-performing others for help (Karabenick \& Gonida, 2018). Yet, our analyses showed unexpected context effects - depending on the help-seeking strategy and subject domain under investigation: while social exclusion predicted higher levels of help-seeking avoidance in the computer sciences, it predicted lower levels of autonomy-oriented help-seeking in education - among both male and female students. Thus, it seems that perceived exclusion plays out differently in both domains: in the computer sciences, perceived exclusion by peers may correspond to students' reluctance to seek help from peers altogether, while education students who feel excluded merely show lower levels of autonomy-oriented help. Again, prevailing beliefs of brilliance in STEM domains provide a plausible explanation (Deiglmayr et al., 2019). Because students perceive a strong pressure to demonstrate competence by solving problems individually, the psychological costs of help-seeking by appearing incompetent may be so high that they are less willing to take the risk of asking others for help (Peeters et al., 2020) - irrespective of their gender.

While the association between perceived peer exclusion and adaptive help-seeking was a central prediction of our research, we had predicted that it should be particularly strong for female students in the computer sciences, given that negative ability-related stereotypes in challenging environments have been shown to increase minority students' receptiveness for social cues (Murphy et al., 2007; Murphy \& Taylor, 2012). We found this for female students' autonomy-oriented help-seeking but not for help-seeking avoidance in the computer sciences. Although female students' overall level of autonomyoriented help-seeking was comparable to that of their male peers in the computer sciences, their inclination to do so was strongly contingent on their perceived exclusion from social and academic activities. The finding that females in computer science (but not males in education) sought less autonomy-oriented help when feeling excluded could suggest that they are aware of their inferior academic status in this context and more strongly weigh the psychological risks rather than the benefits of seeking help.

Taken together, our results point to the importance of considering feelings of exclusion - particularly in students' first year at university - because they can find their expression in less adaptive help-seeking strategies. Although peer and helping relations have been found to positively predict adaptive study outcomes (e.g., Buhs, 2005; Flook et al., 2005; Ryan \& Shim, 2012; Webb \& Mastergeorge, 2003), they can be difficult to form, particularly among those who feel rejected and excluded.

Although not the focus of our analyses, some interesting findings emerged for academic self-efficacy, which we had included in our regression model as a covariate. Selfefficacy predicted autonomy-oriented help-seeking, albeit only in the computer sciences and not in education. Although this finding needs to be replicated, it suggests that in STEM classrooms, self-efficacy can help students to take the risk and overcome the barrier of asking competent others for help - but only if the type of help provided increases their autonomy to solve future tasks by themselves. This is complemented by the finding that self-efficacy was strongly and negatively related to dependency-oriented help-seeking - in both domains. It seems that higher self-efficacy beliefs are incompatible with help-seeking strategies that do not increase or underscore students' autonomy. Particularly in challenging STEM environments, it seems to match with the perception of (autonomy-oriented) help-seeking as a selfregulated learning strategy.

\section{Gendered Patterns of Helping Relations?}

Much research has shown that female students form more adaptive helping relations than male students (e. g., Kiefer \& Shim, 2016; van Rijsewijk et al., 2016). Our study replicates this finding in the overall sample: female students reported higher levels of autonomyoriented help-seeking and lower levels of help-seeking avoidance than male students. Yet, a closer look shows that these gendered patterns vary depending on the 
subject domain. Only in education but not in the computer sciences do female students seek more adaptive, autonomy-oriented help than male students. Further, female students do not avoid help-seeking more than male students in computer science, though they do so more than females in education. It could be argued that female students perceive their lower status in the computer sciences but not in education. Future research should clarify the extent to which gendered patterns of help-seeking can be explained by a spillover effect of a general learning culture in which work and study progress are understood as an interdependent and collaborative process rather than the result of independent work and competition, the latter of which has been often described for STEM domains (cf. Covarrubias et al., 2019).

\section{Limitations}

Despite the contribution of the present study to our understanding of how feelings of social and academic exclusion matter in different subject domains for male and female students' help-seeking strategies in higher education, the present study is not without limitations pointing to potential avenues for future research.

The main limitation of the present research is that its cross-sectional study design does not allow the exploration of the relationship between exclusion and helpseeking patterns over time. Although we hypothesized that perceptions of exclusion would entail less adaptive help-seeking strategies, it is plausible that students who engage in less adaptive help-seeking are more likely to experience social exclusion. The active withdrawal from student exchanges may very well further increase the perceptions of being an outsider. Alternatively, students may "explain" their reluctance to seek help with their perceived exclusion from others. Cross-lagged designs including more than one point of measurement would help to clarify these interrelations and, thus, inform on the development of appropriate interventions. Based on the current data, we infer that perceptions of exclusion accompany less adaptive help-seeking strategies, suggesting a self-reinforcing cycle that restrains students from unfolding their academic potential. For example, in one study, Smith et al. (2013) created a fictional graduate program. When it was depicted as male-dominated, women expected to exert relatively more effort. When, in another study, effort was communicated as normal and expected to be successful, women reported higher levels of future motivation (Smith et al., 2013). Following this line of argumentation, higher levels of help-seeking avoidance among their fellow students may cause female computer science students to infer that their peers do not need help to succeed. This points to a possible route for improving male and female students' social situation in the computer sciences: the application of interventions targeting the development of adaptive help exchanges among fellow students.

Finally, the current data do not allow us to explore the extent to which different help-seeking strategies may be more or less effective for academic progress in STEM and HEED courses, respectively, given the type of tasks that teachers use in their courses. Another interesting route for future research thus lies in the consideration and systematic investigation of different course setups and the potentially different task types teachers use in STEM and HEED domains as a potential explanation for the prevailing help-seeking strategies in the different domains.

\section{Practical Implications and Future Directions}

Taken together, our pattern of results points to the importance of considering both social and contextual factors when examining students' adaptive academic behaviors. Feeling excluded may hinder students from seeking the support that enables them to master challenging academic situations. Yet, it is not simply the fact of being in a minority that relates to maladaptive learning behavior. Consistent with recent studies, our results point to a rather "chilly" and performance-oriented climate in higher education STEM classrooms where help-seeking may be perceived as less normative. To increase and maintain the share of female students in STEM domains, it remains an important task to identify ways to increase the perception of help-seeking as a legitimate strategy of self-regulated learning, possibly even an important skill for future professional development. It seems plausible that university teachers and lecturers can play an important role by encouraging students to seek and exchange help, e.g., in cooperative learning settings (Webb \& Mastergeorge, 2003) and by emphasizing autonomyoriented help-seeking as an important opportunity to obtain the competencies that are needed to solve future tasks individually or to give advice to other students (Zander et al., 2019). Much evidence supports the positive influence of a classroom's mastery as opposed to performance goal orientation (Karabenick, 2004; Ryan \& Shim, 2012) and emphasis on the malleability of competencies on help-seeking (Ames, 1992; Covarrubias et al., 2019; 
Webb \& Mastergeorge, 2003). Our results suggest that this may be particularly helpful in STEM domains.

Lastly, the fact that, as a numerical minority, only females in the computer sciences but not males in the educational sciences show less adaptive help-seeking when feeling excluded underscores the need to include strategies that enable female STEM students to form and be part of a classroom culture that understands the request and exchange of adaptive academic help as a means for progress and effective learning rather than a sign of intellectual inferiority.

\section{References}

Aiken, L. S., \& West, S. G. (1991). Multiple regression: Testing and interpreting interactions. Sage.

Amemiya, J., \& Wang, M.-T. (2017). Transactional relations between motivational beliefs and help seeking from teachers and peers across adolescence. Journal of Youth and Adolescence, 46(8), 1743-1757. https://doi.org/10.1007/s10964-016-0623-y

Ames, C. (1992). Classrooms: Goals, structures, and student motivation. Journal of Educational Psychology, 84(3), $261-271$. https://doi.org/10.1037/0022-0663.84.3.261

Banchefsky, S., Lewis, K. L., \& Ito, T. A. (2019). The role of social and ability belonging in men's and women's pSTEM persistence. Frontiers in Psychology, 10, 2386. https://doi.org/10. 3389/fpsyg.2019.02386

Baumeister, R. F., \& Leary, M. R. (1995). The need to belong: Desire for interpersonal attachments as a fundamental human motivation. Psychological Bulletin, 117(3), 497 -529. https://doi.org/ 10.1037/0033-2909.117.3.497

Bloodhart, B., Balgopal, M. M., Casper, A. M. A., Sample McMeeking, L. B., \& Fischer, E. V. (2020). Outperforming yet undervalued: Undergraduate women in STEM. PLOS One, 15(6), e0234685. https://doi.org/10.1371/journal.pone.0234685

Borgatti, S. P., \& Lopez-Kidwell, V. (2011). Network theory. In J. C. Scott \& P. J. Carrington (Eds.), The SAGE handbook of social network analysis (pp. 40 -54). Sage.

Brouwer, J., Jansen, E., Flache, A., \& Hofmann, A. (2016). The impact of social capital on self-efficacy and study success among first-year university students. Learning and Individual Differences, 52, 109 -118. https://doi.org/10.1016/j.lindif.2016. 09.016

Brouwer, J., Flache, A., Jansen, E., Hofmann, A., \& Steglich, C. E. G. (2018). Emergent achievement segregation in freshmen learning community networks. Higher Education, 76(3), 483-500. https://doi.org/10.1007/s10734-017-0221-2

Brown, D., Barry, J. A., \& Todd, B. K. (2020). Barriers to academic help-seeking: The relationship with gender-typed attitudes. Journal of Further and Higher Education, 45(3), 401-416. https://doi.org/10.1080/0309877X.2020.1774049

Buhs, E. S. (2005). Peer rejection, negative peer treatment, and school adjustment: Self-concept and classroom engagement as mediating processes. Journal of School Psychology, 43(5), 407-424. https://doi.org/10.1016/j.jsp.2005.09.001

Chernyak-Hai, L., Halabi, S., \& Nadler, A. (2017). Gendered help: Effects of gender and realm of achievement on autonomyversus dependency-oriented help giving. Journal of Social and Political Psychology, 5(1), 117-141. https://doi.org/10.5964/ jspp.v5i1.609
Christie, H., Munro, M., \& Fisher, T. (2004). Leaving university early: Exploring the differences between continuing and non-continuing students. Studies in Higher Education, 29(5), 617-636. https://doi.org/10.1080/0307507042000261580

Cleavenger, D., Gardner, W. L., \& Mhatre, K. (2007). Help-seeking: Testing the effects of task interdependence and normativeness on employees' propensity to seek help. Journal of Business and Psychology, 21(3), 331-359. https://doi.org/10.1007/s10869006-9032-7

Cohen, J. (1988). Statistical power analysis for the behavioral sciences $\left(2^{\text {nd }}\right.$ ed.). Erlbaum.

Covarrubias, R., Laiduc, G., \& Valle, I. (2019). Growth messages increase help-seeking and performance for women in STEM. Group Processes \& Intergroup Relations, 22(3), 434-451. https://doi.org/10.1177/1368430218802958

Degner, J., Mangels, J., \& Zander, L. (2019). Visualizing gendered representations of male and female teachers using a reverse correlation paradigm. Social Psychology, 50(4), 233-251. https://doi.org/10.1027/1864-9335/a000382

Deiglmayr, A., Stern, E., \& Schubert, R. (2019). Beliefs in "brilliance" and belonging uncertainty in male and female STEM students. Frontiers in Psychology, 10, 1114. https://doi.org/10. 3389/fpsyg.2019.01114

Dweck, C. S. (1999). Self-theories: Their role in motivation, personality, and development. Psychology Press.

Federal Statistical Office of Germany (2019). Bildung und Kultur. Studierende an Hochschulen - Wintersemester 2018/19 [Education and culture. Students at universities - winter term 2018/ 19]. Author.

Flook, L., Repetti, R. L., \& Ullman, J. B. (2005). Classroom social experiences as predictors of academic performance. Developmental Psychology, 41(2), 319-327. https://doi.org/10.1037/ 0012-1649.41.2.319

Gopalan, M., \& Brady, S. T. (2020). College students' sense of belonging: A national perspective. Educational Researcher, 49(2), 134-137. https://doi.org/10.3102/0013189X19897622

Heyder, A., \& Kessels, U. (2016). Boys don't work? On the psychological benefits of showing low effort in high school. Sex Roles, 77, 72 - 85. https://doi.org/10.1007/s11199-016-0683-1

Höhne, E., \& Zander, L. (2019). Sources of male and female students' belonging uncertainty in the computer sciences. Frontiers in Psychology, 10, 1740. https://doi.org/10.3389/ fpsyg.2019.01740

Hox, J., van Buuren, S., \& Jolani, S. (2015). Incomplete multilevel data: Problems and solutions. In J. R. Harring, L. M. Stapleton \& S. N. Beretvas (Eds.), Advances in multilevel modeling for educational research: Addressing practical issues found in realworld applications (pp. 39 -62). Information Age Publishing.

IBM Corp. (2017). IBM SPSS Statistics for Windows, version 25.0. Author.

Jerusalem, M., \& Schwarzer, R. (1986). Selbstwirksamkeit [Selfefficacy]. In R. Schwarzer (Ed.), Skalen zur Befindlichkeit und zur Persönlichkeit (pp. 15 -28). Institut für Psychologie, Freie Universität Berlin.

Karabenick, S. A. (2004). Perceived achievement goal structure and college student help seeking. Journal of Educational Psychology, 96(3), 569-581. https://doi.org/10.1037/00220663.96.3.569

Karabenick, S. A., \& Gonida, E. N. (2018). Academic help seeking as a self-regulated learning strategy: Current issues, future directions. In D. H. Schunk \& J. A. Greene (Eds.), Handbook of selfregulation of learning and performance (pp. 421-433). Routledge.

Karabenick, S. A., \& Newman, R. S. (2009). Seeking help: Generalizable self-regulatory process and social-cultural barometer. In M. Wosnitza, S. A. Karabenick, A. Efklides \& P. Nenniger (Eds.), 
Contemporary motivation research: From global to local perspectives (pp. 25 - 48). Hogrefe \& Huber.

Kessels, U., \& Steinmayr, R. (2013). Macho-man in school: Toward the role of gender role self-concepts and help seeking in school performance. Learning and Individual Differences, 23, 234- 240. https://doi.org/10.1016/j.lindif.2012.09.013

Kiefer, S. M., \& Shim, S. S. (2016). Academic help seeking from peers during adolescence: The role of social goals. Journal of Applied Developmental Psychology, 42, 80 -88. https://doi.org/ 10.1016/j.appdev.2015.12.002

Komissarouk, S., Harpaz, G., \& Nadler, A. (2017). Dispositional differences in seeking autonomy- or dependency-oriented help: Conceptual development and scale validation. Personality and Individual Differences, 108, 103 -112. https://doi.org/10.1016/j. paid.2016.12.019

Linnenbrink, E. A., \& Pintrich, P. R. (2003). The role of self-efficacy beliefs in student engagement and learning in the classroom. Reading \& Writing Quarterly, 19(2), 119 -137. https://doi.org/10. 1080/10573560308223

Lomi, A., Snijders, T. A. B., Steglich, C. E. G., \& Torló, V. J. (2011). Why are some more peer than others? Evidence from a longitudinal study of social networks and individual academic performance. Social Science Research, 40(6), 1506-1520. https://doi.org/10.1016/j.ssresearch.2011.06.010

McCabe, C. J., Kim, D. S., \& King, K. M. (2018). Improving present practices in the visual display of interactions. Advances in Methods and Practices in Psychological Science, 1(2), 147 - 165. https://doi.org/10.1177/2515245917746792

Murphy, M. C., Steele, C. M., \& Gross, J. J. (2007). Signaling threat: How situational cues affect women in math, science, and engineering settings. Psychological Science, 18(10), 879-885. https://doi.org/10.1111/j.1467-9280.2007.01995.x

Murphy, M. C., \& Taylor, V. J. (2012). The role of situational cues in signaling and maintaining stereotype threat. In M. Inzlicht \& T. Schmader (Eds.), Stereotype threat: Theory, process, and application (pp. 17-33). Oxford University Press.

Muthén, L. K., \& Muthén, B. O. (1998-2017). Mplus user's guide (8th ed.). Author.

Nadler, A. (2002). Inter-group helping relations as power relations: Maintaining or challenging social dominance between groups through helping. Journal of Social Issues, 58(3), 487-502. https://doi.org/10.1111/1540-4560.00272

Nadler, A. (2015). The other side of helping: Seeking and receiving help. In D. A. Schroeder \& W. G. Graziano (Eds.), The Oxford handbook of prosocial behavior (pp. 307 -328). Oxford University Press.

Nelson-Le Gall, S. A. (1981). Help-seeking: An understudied problem-solving skill in children. Developmental Review, 1(3), 224-246. https://doi.org/10.1016/0273-2297(81)90019-8

Newman, R. S., \& Schwager, M. T. (1995). Students' help seeking during problem solving: Effects of grade, goal, and prior achievement. American Educational Research Journal, 32(2), 352-376. https://doi.org/10.3102/00028312032002352

Nosek, B. A., Banaji, M. R., \& Greenwald, A. G. (2002). Math = male, $m e=$ female, therefore math $\neq$ me. Journal of Personality and Social Psychology, 83(1), 44-59. https://doi.org/10.1037/00223514.83.1.44

Nosek, B. A., Smyth, F. L., Sriram, N., Lindner, N. M., Devos, T., Ayala, A., Bar-Anan, Y., Bergh, R., Cai, H., Gonsalkorale, K., Kesebir, S., Maliszewski, N., Neto, F., Olli, E., Park, J., Schnabel, K., Shiomura, K., Tulbure, B. T., Wiers, R. W., Somogyi, M., Akrami, N., Ekehammar, B., Vianello, M., Banaji, M. R., \& Greenwald, A. G. (2009). National differences in gender-science stereotypes predict national sex differences in science and math achievement. Proceedings of the National Academy of
Sciences of the United States of America, 106(26), 1059310597. https://doi.org/10.1073/pnas.0809921106

Park, H. S. (2008). Centering in hierarchical linear modeling. Communication Methods and Measures, 2(4), 227-259. https://doi.org/10.1080/19312450802310466

Peeters, A., Robinson, V., \& Rubie-Davies, C. (2020). Theories in use that explain adolescent help seeking and avoidance in mathematics. Journal of Educational Psychology, 112(3), 533 550. https://doi.org/10.1037/edu0000423

Peugh, J. L., \& Enders, C. K. (2004). Missing data in educational research: A review of reporting practices and suggestions for improvement. Review of Educational Research, 74(4), 525 - 556. https://doi.org/10.3102/00346543074004525

Pintrich, P. R., \& Zusho, A. (2007). Student motivation and selfregulated learning in the college classroom. In R. P. Perry \& J. C. Smart (Eds.), The scholarship of teaching and learning in higher education: An evidence-based perspective (pp. 731-810). Springer. https://doi.org/10.1007/1-4020-5742-3_16

Rausch, J. L., \& Hamilton, M.W. (2006). Goals and distractions: Explanations of early attrition from traditional university freshmen. The Qualitative Report, 11(2), 317-334. https://doi.org/ 10.46743/2160-3715/2006.1676

Riva, P., \& Eck, J. (Eds). (2016). Social exclusion: Psychological approaches to understanding and reducing its impact. Springer. https://doi.org/10.1007/978-3-319-33033-4

Ryan, A. M., \& Pintrich, P. R. (1997). "Should I ask for help?" The role of motivation and attitudes in adolescents' help seeking in math class. Journal of Educational Psychology, 89(2), 329 - 341. https://doi.org/10.1037/0022-0663.89.2.329

Ryan, A. M., \& Shim, S. S. (2012). Changes in help seeking from peers during early adolescence: Associations with changes in achievement and perceptions of teachers. Journal of Educational Psychology, 104(4), 1122 -1134. https://doi.org/10.1037/ a0027696

Schafer, J. L., \& Graham, J. W. (2002). Missing data: Our view of the state of the art. Psychological Methods, 7(2), 147-177. https:// doi.org/10.1037/1082-989X.7.2.147

Shnabel, N., Bar-Anan, Y., Kende, A., Bareket, O., \& Lazar, Y. (2016). Help to perpetuate traditional gender roles: Benevolent sexism increases engagement in dependency-oriented crossgender helping. Journal of Personality and Social Psychology, 110(1), 55-75. https://doi.org/10.1037/pspi0000037

Smalley, R. T., \& Hopkins, S. (2020). Social climate and helpseeking avoidance in secondary mathematics classes. The Australian Educational Researcher, 47, 445-476. https://doi. org/10.1007/s13384-020-00383-y

Smith, J. L., Lewis, K. L., Hawthorne, L., \& Hodges, S. D. (2013). When trying hard isn't natural: Women's belonging with and motivation for male-dominated STEM fields as a function of effort expenditure concerns. Personality and Social Psychology Bulletin, 39(2), 131 -143. https://doi.org/10.1177/014616721 2468332

Snijders, T. A. B., \& Bosker, R. J. (2012). Multilevel analysis: An Introduction to basic and advanced multilevel modeling ( $2^{\text {nd }}$ ed.). Sage.

Strayhorn, T. L. (2018). College students' sense of belonging: A key to educational success for all students ( $2^{\text {nd }}$ ed.). Routledge.

Tellhed, U., Bäckström, M., \& Björklund, F. (2017). Will I fit in and do well? The importance of social belongingness and selfefficacy for explaining gender differences in interest in STEM and HEED. Sex Roles, 77, 86-96. https://doi.org/10.1007/ s11199-016-0694-y

Thomas, S. L. (2000). Ties that bind: A social network approach to understanding student integration and persistence. The Journal of Higher Education, 71(5), 591-615. https://doi.org/10. $2307 / 2649261$ 
Tymms, P., Merrell, C., \& Henderson, B. (1997). The first year at school: A quantitative investigation of the attainment and progress of pupils. Educational Research and Evaluation, 3(2), 101 - 118. https://doi.org/10.1080/1380361970030201

van Rijsewijk, L., Dijkstra, J. K., Pattiselanno, K., Steglich, C. E. G., \& Veenstra, R. (2016). Who helps whom? Investigating the development of adolescent prosocial relationships. Developmental Psychology, 52(6), 894-908. https://doi.org/10.1037/ dev0000106

Walton, G. M., \& Brady, S. T. (2020). The social-belonging intervention. In G. M. Walton \& A. J. Crum (Eds.), Handbook of wise interventions: How social psychology can help people change (pp. 36 -62). Guilford.

Walton, G. M., \& Cohen, G. L. (2007). A question of belonging: Race, social fit, and achievement. Journal of Personality and Social Psychology, 92(1), 82 - 96. https://doi.org/10.1037/0022-3514. 92.1.82

Walton, G. M., Logel, C., Peach, J. M., Spencer, S. J., \& Zanna, M. P. (2015). Two brief interventions to mitigate a "chilly climate" transform women's experience, relationships, and achievement in engineering. Journal of Educational Psychology, 107(2), 468 485. https://doi.org/10.1037/a0037461

Webb, N. M., \& Mastergeorge, A. (2003). Promoting effective helping behavior in peer-directed groups. International Journal of Educational Research, 39(1-2), 73-97. https://doi.org/10. 1016/S0883-0355(03)00074-0

Wesselmann, E. D., Michels, C., \& Slaughter, A. (2019). Understanding common and diverse forms of social exclusion. In S. C. Rudert, R. Greifeneder \& K. D. Williams (Eds.), Current directions in ostracism, social exclusion and rejection research (pp. 1-17). Routledge.

Zimmerman, B. J., \& Schunk, D. H. (1989). Self-regulated learning and academic achievement: Theory, research, and practice. Springer.

Zander, L., Brouwer, J., Jansen, E., Crayen, C., \& Hannover, B. (2018). Academic self-efficacy, growth mindsets, and university students' integration in academic and social support networks. Learning and Individual Differences, 62, 98-107. https://doi. org/10.1016/j.lindif.2018.01.012

Zander, L., Chen, I., \& Hannover, B. (2019). Who asks whom for help in mathematics? A sociometric analysis of adolescents' help-seeking within and beyond clique boundaries. Learning and Individual Differences, 72, 49-58. https://doi.org/10.1016/ j.lindif.2019.03.002

Zander, L., \& Höhne, E. (2021). Too good to belong: Kompetenzbezogene und soziale Prädiktoren des Zugehörigkeitsgefühls im Lehramtsstudium Sonderpädagogik [Too good to belong: Competence-related and social predictors of belongingness among special needs education teachers in training]. In D. Raufelder \& G. Hagenauer (Hrsg.), Soziale Eingebundenheit - Sozialbeziehungen im Fokus von Schule und Lehrer*innenbildung (pp. 237 252). Waxmann.

Zander, L., Kreutzmann, M., \& Hannover, B. (2017). Peerbeziehungen im Klassenzimmer [Peer relations in the classroom]. Zeitschrift für Erziehungswissenschaft, 20(3), 353-386. https://doi.org/10.1007/s11618-017-0768-9

Zusho, A., \& Barnett, P. A. (2011). Personal and contextual determinants of ethnically diverse female high school students' patterns of academic help seeking and help avoidance in English and mathematics. Contemporary Educational Psychology, 36(2), 152-164. https://doi.org/10.1016/j.cedpsych.2011. 02.002

\section{Funding}

Open access publication enabled by Technische Informationsbibliothek (TIB).

\section{Elisabeth Höhne}

Division of Empirical Educational Research

Institute of Education

Leibniz Universität Hannover

Schloßwender Straße 1

30159 Hannover

elisabeth.hoehne@iew.uni-hannover.de

\section{ORCID}

Lysann Zander

(D) https://orcid.org/0000-0001-7075-3436

Elisabeth Höhne

(D) https://orcid.org/0000-0003-3008-5060 